\title{
Schiţă ermineutică privind atitudinea antiiudaică a Sfântului Roman Melodul în cele şase condace la Învierea Domnului
}

\author{
Alexandru PRELIPCEAN *
}

\begin{abstract}
Hermeneutic sketch on the anti-Jewish attitude of Saint Romanos the Melodist in the six kontakia at the Resurrection of the Lord. The present study, which is intended to be perceived as a hermeneutic sketch, is a succinct foray into the six condas composed by the Romanos the Melodist in the sixth century and dedicated to the Resurrection of the Lord. Of course, the perspective we are looking for is the (supposed?) Anti-Jewish attitude of the Byzantine hymnographer. We probe this vision in the six kontakia, following the passages where Romanos speaks directly about the Jews and finally looking
\end{abstract} for their theological value.

Keywords: Romanos the Melodist, hymnography, jews, kontakia, Resurrection

\section{Discuţii preliminare}

Literatura patristică contemporană a dezvoltat numeroase palete ermineutice cu privire la operele Sfântului Roman Melodul (cca. 480-555): de la valorificarea Bios-ului romaneic la identificarea unor opere cu pretenţia de genuina, de la teologia condacelor sale la aspecte filologice, de la relaţia sa cu Imnul Acatist până la teze de doctorat dedicate unor nuanţe teologice concrete $^{1}$. Stric legat însă de subiectul spinos a atitudinii antiiudaice

" Asistent universitar la Facultatea de Teologie Ortodoxă „Dumitru Stăniloae”, Universitatea „Alexandru Ioan Cuza” din Iaşi, România.

${ }^{1} \mathrm{O}$ identificare pe larg cu privire la aceste aspecte, vezi în bibliografia noastră dedicată Sfântului Roman Melodul: „Romanos' Renaissance”. From the 
a Sfântului Roman, nu cunoaştem până astăzi existenţa vreunui studiu concret, cu excepţia lapidarelor inserări despre elementele

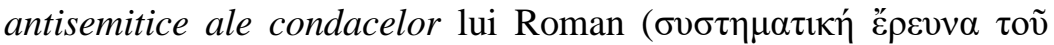

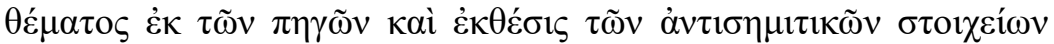

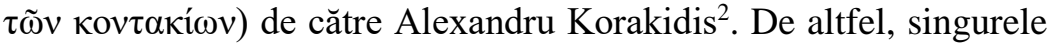
treceri în revistă ale unor opinii (mai mult sau mai puţin pertinente) le avem numai în relaţie cu presupusa origine iudaică a

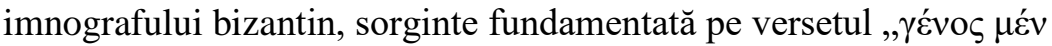
¿̇ $\xi \dot{\varepsilon} \rho \alpha i \omega v "$ (din neamul evreilor) din cuprinsul unui imn encomiastic, alcătuit fie de Gherman al Constantinopolului, fie de un anonim, fie de Alexandru Eumorphopoulos ${ }^{3}$.

Ceea ce îşi propune studiul acesta este să identifice elementele antiiudaice ale lui Roman în cadrul celor şase condace dedicate Invierii Domnului ${ }^{4}$, să le clasifice şi să le interpreteze în lumina cercetărilor contemporane dedicate acestor condace romaneice ${ }^{5}$ şi

beginning to the present. Bibliography about Romanos the Melodist, With a preface by Martin Tamcke (Studien zur Orientalischen Kirchengeschichte, 61), Berlin-Münster-Wien-Zürich-London, LIT Verlag, 2019.

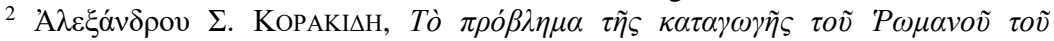

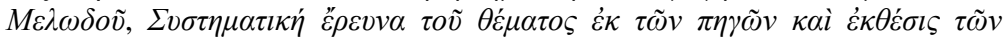

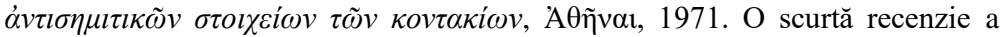
acestei cărţi vezi în studiul nostru: „Гर́vo $\_\mu$ ćv $\dot{\varepsilon} \xi \dot{\varepsilon} \beta \rho \alpha i ́ \omega v$ or the Jewish origin of Romanos the Melodist: From overestimations to underestimations and finding bridges between the West and the Orient", în Review of Ecumenical Studies 2 (2019), p. 204-205.

${ }^{3} \mathrm{Cu}$ privire la bibliografia pentru subiectul acesta şi multiplele erminii, vezi studiul nostru: „Гर́vo $\mu$ \&́v $\dot{\varepsilon} \xi \dot{\varepsilon} \beta \rho \alpha i \omega v$ or the Jewish origin of Romanos the Melodist...", p. 199-208.

4 Pentru ediţiile critice am folosit: Paul MAAS, C.A. Trypanis (ed.), Sancti Romani Melodi Cantica. Cantica genuina, Oxford, Clarendon Press, 1963, p. 181-233 (condacele 24-29) şi José Grosdidier DE MATONs (ed.), Romanos le Mélode. Hymnes (Sources Chrétiennes, 128), Paris, Les Éditions du Cerf, 1967, p. 378-601 (condacele XL-XLV); pentru traducerea în limba română: Sfântul Roman Melodul, Imne, trad. Cristina Rogobete şi Sabin Preda, Bucureşti, Edit. Bizantină, 2007, p. 194-300. Pentru o uşoară identificare în studiul acesta vom folosi cifrele arabe pentru condacele din ediţia lui Maas/Trypanis, iar pe cele romane pentru condacele lui J.G. de Matons, urmate de indicarea strofei şi a versetelor.

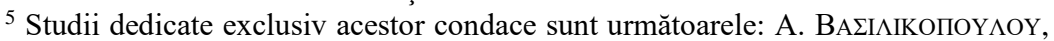

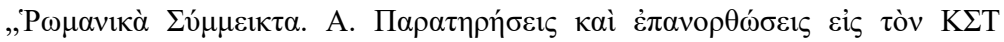


problematicii (imnografice) antiiudaice, în general ${ }^{6}$. Nu ne propunem aici să redăm în mod exhaustiv problematica antiiudaică a

v̋ Graz, 1965, p. 217-224; P. VAN SICHEM, „Een opstandingskontakion van Romanos de Melode als voorbeld van zijn dichtkunst", în R. THIBAU, H. DE LEY (ed.), Avó $\mu v \eta \sigma ı \varsigma, ~ G e d e n k b o e k$ E. A. Leemans, Brügge, 1970, p. 385-400;

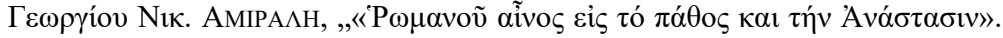

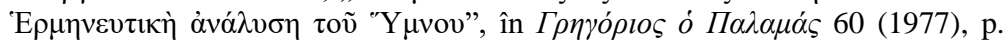
112-121; Mihail VoICESCU, ,Învierea Domnului în creaţia imnografică a Sfântului Roman Melodul”, în Glasul Bisericii 4-5 (1983), p. 239-250; J.H. BARKHUIZEN, „Romanos Melodos: Essay on the Poetics of his Kontakion «Resurrection of Christ» (Maas-Trypanis 24)", în Byzantinische Zeitschrift 79 (1986), p. 17-28; partea a II-a, p. 268-281.

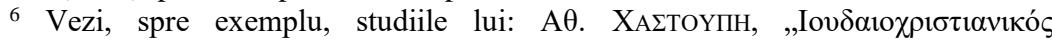

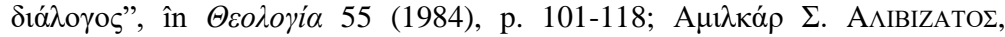

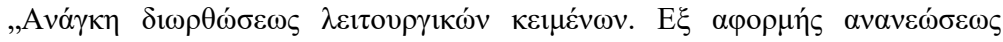

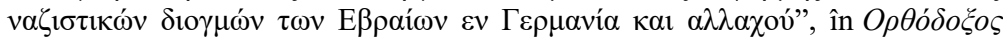
$\sum \kappa \varepsilon ́ \psi \imath \iota, 3$ (1960), p. 5-8; Thomas KRATZERT, „Wir sind wie die Juden”: Der griechisch-orthodoxe Beitrag zu einem ökumenischen jüdisch-chrislichen Dialog, Istitut Kirche und Judentum, Berlin, 1994; BARTOLOMEO I, „Gli ortodossi e l'ebraismo", în Gloria a Dio per ogni cosa, Ed. Qiqajon, 2001; Pavlos Koumarianos, „Liturgical Problems of Holy Week”, în St. Vladimir's Theological Quaterly 46 (2002), p. 3-21; Elizabeth THEOKRITOFF, „The Orthodox services of Holy Week: The Jews and the New Sion", în Sobornost incorporating Eastern Churches Review 25 (2003), p. 25-50; I $\omega$ óvvov

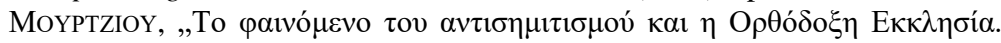

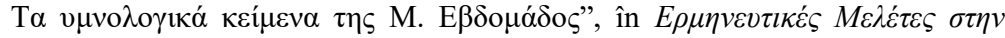

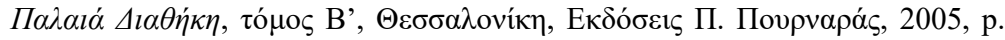
23-38 [trad. rom.: „Fenomenul antisemitismului şi Biserica Ortodoxă. Textele liturgice ale Săptămânii Patimilor”, trad. Alexandru Prelipcean, în Alexandru IONIȚĂ (ed.), Imnografia liturgică bizantină. Perspective critice (Studia Oecoumenica, 13), Cluj-Napoca, Presa Universitară Clujeană, 2019, p. 39-51]; Bert Groen, „Attitudes towards Judaism in Greek-Byzantine Liturgy: AntiJudaism in Holy Weeks Text and the Appreciation of Israel's Righteous", în Analecta Bruxellensia 12 (2007), p. 81-93; IDEM, „Anti-Judaism in the PresentDay Byzantine Liturgy", în Journal of Eastern Christian Studies 60 (2008), p.

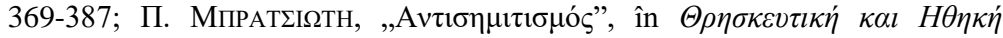

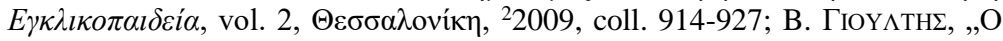

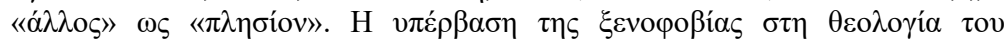

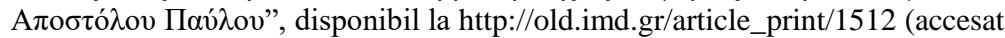
la data de 29.11.2020); Mireille COHEN, Sandrine CANERI, „Recontextualiser les Saints Pères et ne pas juger", în Sens 384 (2013), p. 843-849; Eugen J. 
imnografiei romaneice, ci să fie o schiţă ermineutică de la care sperăm să întocmim în viitor un studiu cât mai amplu dedicat acestui subiect extrem de pretenţios.

PENTIUC, „Orthodoxy and Judaism”, în John Anthony McGuckin (ed.), The Concise Encyclopedia of Orthodox Christianity, Wiley Blackwell, 2014, p. 286-288; Michael G. AzAR, „Prophetic Matrix and Theological Paradox: Jews and Judaism in the Holy Week and Pascha Observances of the Greek Orthodox Church", în Studies in Christian-Jewish Relations 1 (2015), disponibil la https://ejournals.bc.edu/index.php/scjr/article/view/8658 [accesat la data de 19.09.2020; trad. rom.: „Matrice profetică şi paradox teologic: evrei şi iudaism în Săptămâna Mare, precum şi ritualurile pascale în Biserica Ortodoxă”, trad. Alexandru Prelipcean, în Alexandru IonițĂ (ed.), op. cit., p. 11-38]; Bogdan G. BuCUR, „Anti-Jewish Rhetoric in Byzantine Hymnography: Exegetical and Theological Contextualization", în St. Vladimir's Theological Quaterly 1 (2017), p. 39-60 [trad. rom.: „Retorica anti-iudaică din imnografia bizantină: Contextualizare exegetică şi teologică”, în Alexandru Ioniță (ed.), op. cit., p. 52-77]; Alexandru IoniȚĀ, „Old Wine in New Wineskins: Romans 9-11 as a Possible Biblical Source for a New Hymnography of the Holy Week", în Ivan Moody, Maria TAKALA-RoszCZENKo (ed.), Creating Liturgically: Hymnography and Music. Proceedings of the Sixth International Conference on Orthodox Church Music, University of Eastern Finland, Joensuu 8-14 June 2015, The International Society for Orthodox Church Music, 2017, p. 228-243 [trad. rom.: „Vin vechi în burdufuri noi: Romani 9-11 ca sursă de inspiraţie pentru noi creaţii imnografice", în Alexandru IonIŢă (ed.), op. cit., p. 95-120]; IDEM, „Patristic and Eastern Orthodox Interpretations of Romans 9-11: Overview and Perspectives for the Theological Recovery of a Pauline Text", in Benyik GyörGY (ed.), Interpretations of the Letter to the Romans, Szeged, Jate Press 2018, p. 113-123; IDEM, „Byzantine Liturgical Hymnography: a Stumbling Stone for the Jewish-Orthodox Christian Dialogue?", în Review of Ecumenical Studies 2 (2019), p. 253-267; Michael G. AzAR, „Jewish-Christian Relations and Orthodox Ecumenical Participation", în Public Orthodoxy. The Orthodox Christian Study Center of Fordham University, disponibil la https://publicorthodoxy.org/2015/10/22/jewish-christian-relations-and-orthodoxecumenical-participation/ (accesat la data de 19.09.2020); Amy-Jill LEVINE, „Holy Week and the hatred of the Jews: How to avoid anti-Judaism this Easter", disponibil la https:/www.abc.net.au/religion/holy-week-and-thehatred-of-the-jews/11029900 (accesat la data de 19.09.2020); Bogdan BuCUR, „The Murderers of God, The Lawless Nation of the Jews...: Coming to Grips with Some of Our Holy Week Hymns", în Public Orthodoxy, disponibil la https://publicorthodoxy.org/2018/03/29/bucur-holy-week-2018/ (accesat la data de 19.09.2020). 


\section{Identificarea pasajelor antiiudaice în condacele pascale}

În afara prooimionului I (,Deşi Te-ai pogorât în

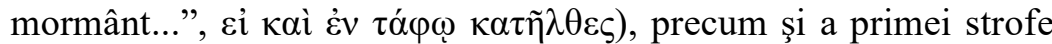
din condacul al VI-lea al Învierii („Pe Soarele cel mai înainte de

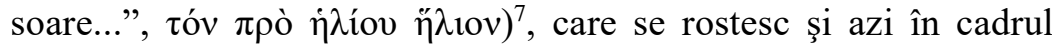
Utreniei de la Paşti ${ }^{8}$, alte pasaje ale condacelor romaneice dedicate sărbătorii pascale, care să fie cuprinse astăzi în cultul divin public, nu există. Desigur, cele mai multe identificări ale acestei perpective antiiudaice trebuie căutate în mod direct în problematica istorică a Săptămânii Pătimirilor, din care Melodul îşi extrage mesajul său privind rolul răstignirii asupra mântuirii omului ${ }^{9}$. Identificarea de mai jos, pe care o extindem prin inserarea întregului fragment romaneic, este elocventă din patru perspective ermineutice, şi anume: a) ajută la enunţarea erminiei poetului bizantin în legătură cu iudeiii din epoca Mântuitorului; b) clasifică epitetele imnografice adresate evreilor; c) identifică relaţia iudeilor cu Hristos şi contextul istoric în care a avut loc moartea pe Cruce a Mântuitorului, având la bază textul scripturistic; d) pune în paralel mentalitatea căpeteniilor iudaice din epoca lui Hristos şi mentalitatea ereticilor din epoca lui Roman.

${ }^{7}$ Paul MAas, C.A. TryPanis (ed.), op. cit., 29, p. 181-182; José GrosDidiER DE MATONS (ed.), op. cit., XL, p. 380-382. La cei doi editori diferă numerotarea condacelor cu tematică pascală (la Maas şi Trypanis este ultimul condac, în timp ce la J.G. de Matons e primul din seria pascală). Am dat întâietate ediţiei lui Maas şi Trypanis datorită publicării anterioare ediţiei pariziene.

8 ***, Penticostarul, Adică sfintele slujbe de la Duminica Paştilor până la Duminica Sfinţilor români, Bucureşti, Edit. Institutului Biblic şi de Misiune Ortodoxă, 2012, p. 18-19. Textele acestea se repetă la toate Utreniile din Săptămâna luminată, cu excepţia zilei de Vineri (Izvorul tămăduirii), care are condac şi icos deosebit.

${ }^{9}$ Sarah Elizabeth GADOR-WHYTE, Rhetoric and Ideas in the Kontakia of Romanos the Melodist, Submitted in total fulfilment of the requirements of the degree of Doctor of Philosophy, Center for Classics and Archaeology, The University of Melbourne, 2011, p. 46 (în manuscris). 


\begin{tabular}{|c|c|c|}
\hline $\begin{array}{c}\text { Condac } \\
\text { (ediţia Maas, } \\
\text { Trypanis/J.G. } \\
\text { de Matons) }\end{array}$ & Text romaneic & Traducere \\
\hline 24/XLIa ${ }^{3}$ & 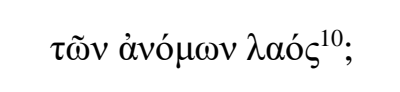 & $\begin{array}{l}\text { „Poporul cel fără de } \\
\text { lege" } 11 ;\end{array}$ \\
\hline $24 / \mathrm{XLI}^{7}$ & $\begin{array}{c}\dddot{\omega} \alpha \dot{\alpha} \varphi \rho о \sigma v ́ v \eta \varsigma \tau \tilde{\omega} v \\
\dot{\alpha} v o ́ \mu \omega v^{12} ;\end{array}$ & $\begin{array}{c}\text { „O, nebunie a celor } \\
\text { fără de lege" }{ }^{13} \text {; }\end{array}$ \\
\hline $24 / \mathrm{XLI} \gamma^{1-2}$ & 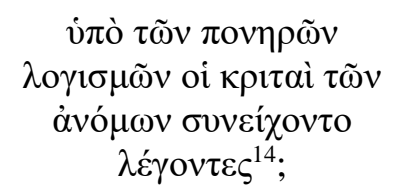 & $\begin{array}{c}\text { „De gânduri rele fiind } \\
\text { adunaţi, judecătorii } \\
\text { celor fără de lege îşi } \\
\text { ziceau”15; }\end{array}$ \\
\hline $24 / \mathrm{XLI} \varepsilon^{6}$ & 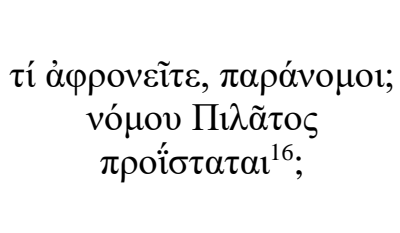 & $\begin{array}{c}\text { „Ce cugetaţi voi } \\
\text { nebuneşte, o, } \\
\text { călcătorilor de lege? } \\
\text { Pilat e începătorul } \\
\text { legii?”17; }\end{array}$ \\
\hline 24/XLIi $\alpha^{1-3}$ & 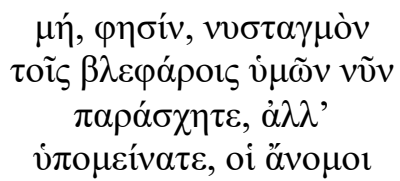 & $\begin{array}{l}\text { „Nu daţi somn } \\
\text { ploapelor voastre, nu } \\
\text { daţi acum, ci mai } \\
\text { răbdaţi!" au zis atunci }\end{array}$ \\
\hline
\end{tabular}

${ }^{10}$ Paul MaAs, C.A. TRYPANis (ed.), op. cit., p. 181; José GrosDidiER DE MATONS (ed.), op. cit., p. 432.

11 Sfântul Roman Melodul, op. cit., p. 220.

12 Paul MaAs, C.A. TRYPANIS (ed.), op. cit., p. 181; José GROSDIDIER DE MATONS (ed.), op. cit., p. 432.

13 Sfântul Roman Melodul, op. cit., p. 220.

${ }^{14}$ Paul MaAs, C.A. TRYPANIS (ed.), op. cit., p. 182; José GrosDidiER DE MATONS (ed.), op. cit., p. 434.

15 Sfântul Roman Melodul, op. cit., p. 221.

${ }^{16}$ Paul MAAS, C.A. TRYPANIS (ed.), op. cit., p. 182; José GROSDIDIER DE MATONS (ed.), op. cit., p. 434.

${ }^{17}$ Sfântul Roman Melodul, op. cit., p. 222. 
Schiţă ermineutică privind atitudinea antiiudaică a Sfântului Roman Melodul în cele şase condace la Învierea Domnului

\begin{tabular}{|c|c|c|}
\hline & 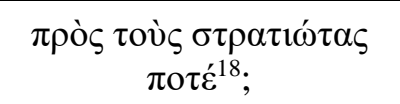 & $\begin{array}{c}\text { nelegiuiţii către } \\
\text { ostaşi }^{19} ;\end{array}$ \\
\hline $24 / \mathrm{XLI} \gamma^{1-2}$ & 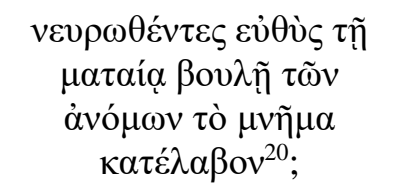 & $\begin{array}{l}\text { „Întărâtaţi pe dată cu } \\
\text { deşertul sfat al celor } \\
\text { fără de lege, străjerii } \\
\text { venit-au la mormânt"21; }\end{array}$ \\
\hline $24 / \mathrm{XLI} \theta^{1-2}$ & 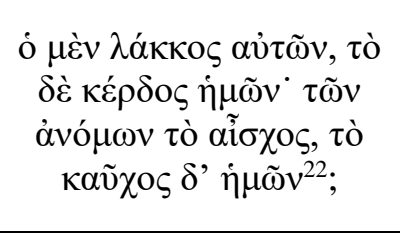 & $\begin{array}{l}\text { „Iată paguba lor şi } \\
\text { răsplătirea noastră, } \\
\text { ruşine pentru cei fără } \\
\text { de lege şi laudă pentru } \\
\text { noi”23; }\end{array}$ \\
\hline $25 \kappa^{1-2} / \mathrm{XLII}^{1}$ & 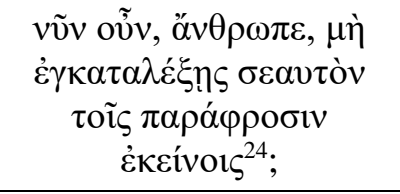 & $\begin{array}{l}\text { „Acum, deci, omule, să } \\
\text { nu te numeri pe sine } \\
\text { cu-acei necugetaţi”25; }\end{array}$ \\
\hline $28 \varepsilon^{1-2} / \mathrm{XLIII} \varepsilon^{2-3}$ & 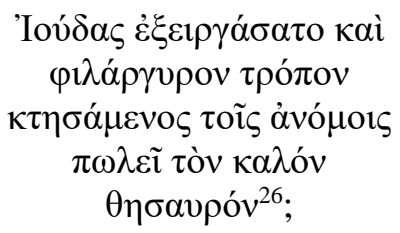 & $\begin{array}{l}\text { „Iuda lucrat-a vicleşug; } \\
\text { şi, iubitor de argint } \\
\text { făcându-se, celor fără } \\
\text { de lege vinde visteria } \\
\text { cea frumoasă"27; }\end{array}$ \\
\hline
\end{tabular}

18 Paul MaAs, C.A. Trypanis (ed.), op. cit., p. 184; José GrosdidiER DE MATONS (ed.), op. cit., p. 440.

${ }^{19}$ Sfântul Roman Melodul, op. cit., p. 225.

${ }^{20}$ Paul MAas, C.A. TRYPANIS (ed.), op. cit., p. 185; José Grosdidier DE MATONS (ed.), op. cit., p. 442.

${ }^{21}$ Sfântul Roman MElodul, op. cit., p. 226.

22 Paul MaAs, C.A. Trypanis (ed.), op. cit., p. 186; José Grosdidier DE MATONS (ed.), op. cit., p. 448.

${ }^{23}$ Sfântul Roman Melodul, op. cit., p. 229.

${ }^{24}$ Paul MaAs, C.A. TryPanis (ed.), op. cit., p. 195; José Grosdidier DE MATONS (ed.), op. cit., p. 478.

${ }^{25}$ Sfântul Roman MElodul, op. cit., p. 243.

${ }^{26}$ Paul MAas, C.A. Trypanis (ed.), op. cit., p. 212; José Grosdidier DE MATONS (ed.), op. cit., p. 506.

27 Sfântul Roman MElodul, op. cit., p. 250. 


\begin{tabular}{|c|c|c|}
\hline $28 \varsigma^{1-5} / \mathrm{XLIII}^{1-6}$ & 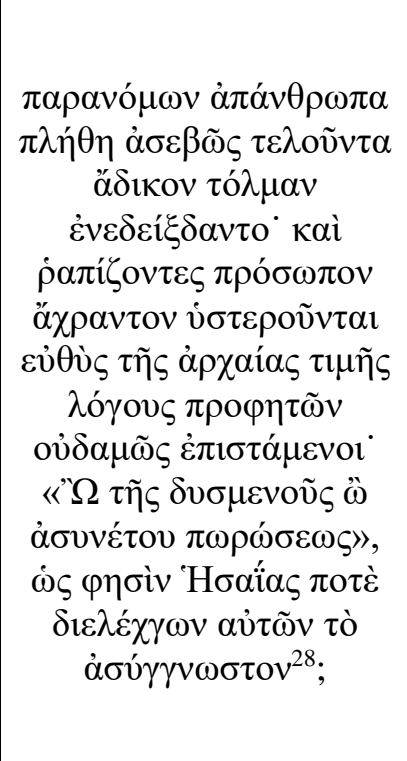 & $\begin{array}{l}\text { „Mulţimile fără de } \\
\text { omenie ale } \\
\text { nelegiuiţilor care în } \\
\text { chip necuvios lucrat- } \\
\text { au, nedreaptă } \\
\text { îndrăzneală arătând şi } \\
\text { pălmuind neprihănita } \\
\text { faţă, pe dat-au fost } \\
\text { lipsiţi de cinstea de } \\
\text { odinioară nemaiştiind } \\
\text { nicicum cuvintele } \\
\text { proorocilor. O, } \\
\text { duşmănie! O, ce } \\
\text { prostească împietrire! } \\
\text { Precum a zis odinioară } \\
\text { Isaia vădind greşeala } \\
\text { lor de neiertat”29; }\end{array}$ \\
\hline $28 \zeta^{1-8} / X_{L I I I} \zeta^{1-9}$ & 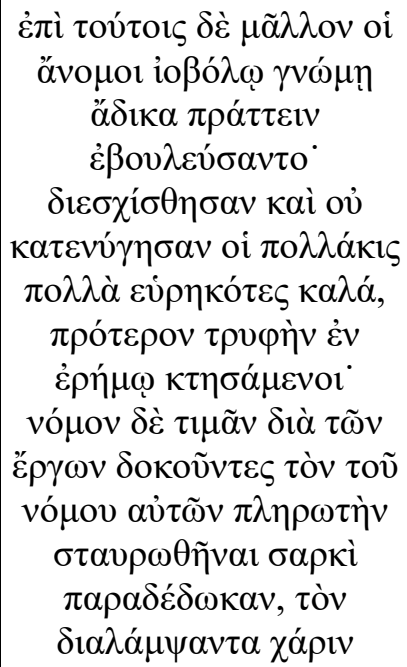 & $\begin{array}{l}\text { „După aceia, cei fără } \\
\text { de lege cu voia lor cea- } \\
\text { nveninată nedrept } \\
\text { lucrat-au, precum au } \\
\text { voit. S-au lepădat şi nu } \\
\text { s-au pocăit, ei care } \\
\text { adesea multe faceri de } \\
\text { bine au aflat. Întâi, } \\
\text { hrană-n pustiu având, } \\
\text { apoi, părându-li-se că } \\
\text { Legea o cinstesc prin } \\
\text { fapte, pe Plinitorul } \\
\text { Legii lor l-au dat să fie } \\
\text { răstignit cu trupul, pe } \\
\text { Cel care le-a strălucit }\end{array}$ \\
\hline
\end{tabular}

${ }^{28}$ Paul MaAs, C.A. TRYPanis (ed.), op. cit., p. 212; José Grosdidier DE Matons (ed.), op. cit., p. 508.

${ }^{29}$ Sfântul Roman MELOdUL, op. cit., p. 251. 


\begin{tabular}{|c|c|c|}
\hline & 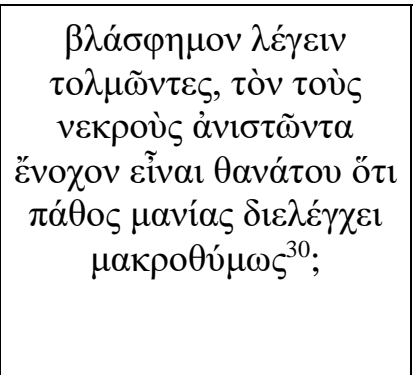 & $\begin{array}{l}\text { lor harul au îndrăznit a- } \\
\text { L socoti un hulitor, pe } \\
\text { Cel care i-a înviat pe } \\
\text { morţi a fi un vinovat de } \\
\text { moarte. Căci îndelung } \\
\text { răbdând le dovedeşte } \\
\text { patima nebuniei } \\
\text { lor..." }{ }^{31} \text {; }\end{array}$ \\
\hline $28 \eta^{6-7} /$ XLIII $\eta^{7-8}$ & 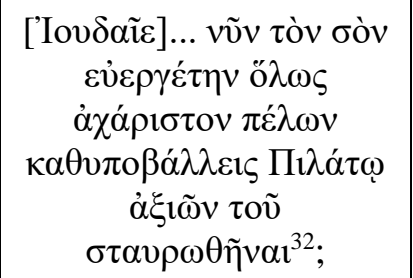 & $\begin{array}{l}\text { [iudeule]..., ,acum cu } \\
\text { totul nemulţumitor } \\
\text { fiind, pe binefăcătorul } \\
\text { tău L-ai dat puterii lui } \\
\text { Pilat, învrednicindu-L } \\
\quad \text { a fi răstignit"33; }\end{array}$ \\
\hline $28 \theta^{1-5} /$ XLIII $^{1-6}$ & 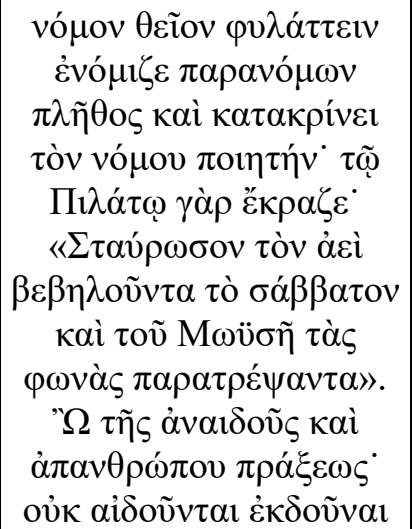 & $\begin{array}{l}\text { „Dumnezeiasca lege } \\
\text { credea că o păzeşte } \\
\text { mulţimea celor fără de } \\
\text { lege şi-a osândit pe } \\
\text { Făcătorul legii, căci lui } \\
\text { Pilat striga: Îl } \\
\text { răstigneşte pe Cel ce- } \\
\text { odinioară sâmbăta a } \\
\text { călcat şi a răstălmăcit } \\
\text { cuvintele lui Moise. O, } \\
\text { faptă fără de ruşine şi } \\
\text { fără omenie! Nu s-au }\end{array}$ \\
\hline
\end{tabular}

30 Paul MaAs, C.A. Trypanis (ed.), op. cit., p. 212-213; José GROSDIDIER DE MATONS (ed.), op. cit., p. 508-510.

${ }^{31}$ Sfântul Roman Melodul, op. cit., p. 251-252.

${ }^{32}$ Paul MaAs, C.A. Trypanis (ed.), op. cit., p. 213; José Grosdidier de Matons (ed.), op. cit., p. 510.

${ }^{33}$ Sfầntul Roman Melodul, op. cit., p. 253. 


\begin{tabular}{|c|c|c|}
\hline & 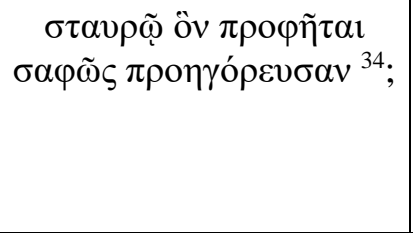 & $\begin{array}{l}\text { dat înapoi a-L da spre } \\
\text { răstignire pe Cel pe } \\
\text { care proorocii mai } \\
\text { înainte L-au vestit în } \\
\text { chip prealămurit"35; }^{\text {ant }}\end{array}$ \\
\hline 28/XLIIIt ${ }^{1}$ & 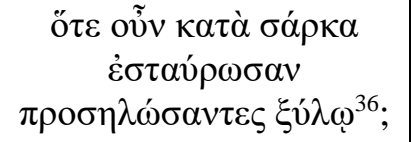 & $\begin{array}{l}\text { „Când după trup L-au } \\
\text { răstignit, pe lemn ei } \\
\text { ţintuindu-L" }\end{array}$ \\
\hline $28 \mathrm{t}^{6-7} / \mathrm{XLIII}^{7-8}$ & 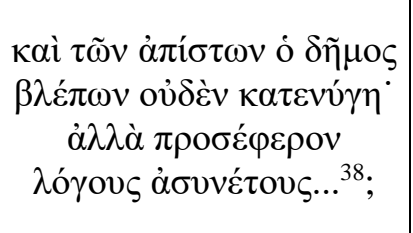 & $\begin{array}{c}\text { „Poporul celor } \\
\text { necredincioşi văzând, } \\
\text { deloc nu s-au căit, ci } \\
\text { aduceau cuvinte } \\
\text { nebuneşti..."39; }\end{array}$ \\
\hline $281 \alpha^{1-2} / \mathrm{XLIII} 1 \alpha^{1-3}$ & 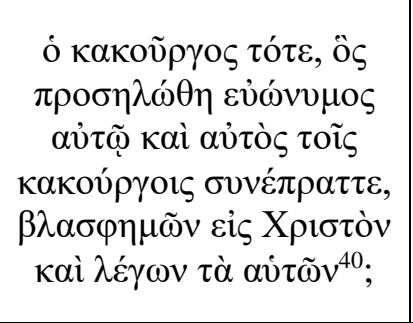 & $\begin{array}{l}\text { „Cel făcător de lege } \\
\text { atunci care pe cruce era } \\
\text { pironit de-a stânga Lui, } \\
\text { şi el se alătură } \\
\text { răufăcătorilor, hulindu- } \\
\text { L pe Hristos şi vorbele } \\
\text { acelora zicând”41; }\end{array}$ \\
\hline
\end{tabular}

După cum observăm din tabelul de mai sus doar două dintre cele şase condace romaneice la sărbătoarea pascală $(24,28 /$ XLI,

34 Paul MaAs, C.A. TryPanis (ed.), op. cit., p. 213; José GrosDidier DE MATONS (ed.), op. cit., p. 510-512.

35 Sfântul Roman Melodul, op. cit., p. 253.

${ }^{36}$ Paul MaAs, C.A. Trypanis (ed.), op. cit., p. 214; José GrosDidier DE MATONS (ed.), op. cit., p. 512.

37 Sfântul Roman MELODUL, op. cit., p. 254.

${ }^{38}$ Paul MAAS, C.A. TRYPANIS (ed.), op. cit., p. 214; José GrosDidiER DE MATONS (ed.), op. cit., p. 512.

39 Sfântul Roman MELODUl, op. cit., p. 254.

${ }^{40}$ Paul MaAs, C.A. TryPanis (ed.), op. cit., p. 214; José GrosDidiER DE MATONS (ed.), op. cit., p. 514.

41 Sfântul Roman MELOdUL, op. cit., p. 255. 
XLIII) folosesc expresii şi epitete atribuite în mod special căpăteniilor poporului iudaic. Condacul 24 (XLI) foloseşte cu

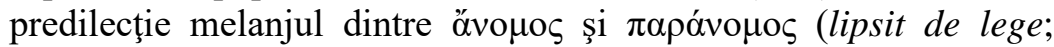
fărădelege; nelegiuit), în timp ce condacul 28 (XLIII) dezvoltă nu mai puţin de şase forme care pendulează între poporul iudeu şi conducătorii lor: celebrul de acum ö́vouos ca epitet adversativ faţă

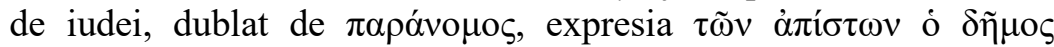

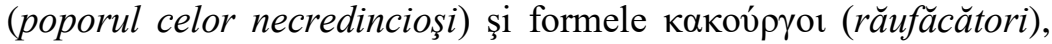

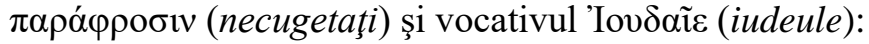

\begin{tabular}{|c|c|c|}
\hline $\begin{array}{l}\text { Termen- } \\
\text { concept/ } \\
\text { expresie }\end{array}$ & Identificare & $\begin{array}{c}\text { Numărul } \\
\text { identificărilor }\end{array}$ \\
\hline övouos & $\begin{array}{c}\text { 24/XLI } \alpha^{3}, 24 / \mathrm{XLI}^{7}, 24 / \mathrm{XLI} \gamma^{2} \\
24 / \mathrm{XLI} \alpha^{3}, 24 / \mathrm{XLI} \gamma^{2}, 24 / \mathrm{XLI} \theta^{2} \\
28 \varepsilon^{2} / \mathrm{XLIII} \varepsilon^{3}, 28 / \mathrm{XLIII} \zeta^{1}\end{array}$ & 8 \\
\hline$\pi \alpha \rho \alpha ́ v o \mu \rho \varsigma$ & $\begin{array}{c}24 / \mathrm{XLI} \varepsilon^{6} \\
28 / \mathrm{XLIII}^{1}, 28 / \mathrm{XLIII}^{1}\end{array}$ & 3 \\
\hline$\pi \alpha \rho \alpha ́ \varphi \rho о \sigma \imath v$ & $25 \kappa^{1-2} /$ XLII $\kappa^{1}$ & 1 \\
\hline $\begin{array}{c}\tau \tilde{\omega} \nu \dot{\alpha} \pi i ́ \sigma \tau \omega \nu \dot{o} \\
\delta \tilde{\eta} \mu \mathrm{s}\end{array}$ & $281^{6} / \mathrm{XLIII}^{7}$ & 1 \\
\hline какои́рүо & $281 \alpha^{2} / \mathrm{XLIII} 1 \alpha^{3}$ & 1 \\
\hline 'Iov $\delta \alpha \tilde{\imath} \varepsilon$ & $28 \eta^{1} / \mathrm{XLIII}^{2}$ & 1 \\
\hline
\end{tabular}

Ceea ce am prezentat aici sunt strict termenii pe care poetul bizantin îi foloseşte în relaţie directă cu iudeii. Desigur, această viziunea teologico-poetică a lui Roman faţă de evrei poate fi observată în mod voalat în diferite secţiuni narative din celalalte condace, chiar dacă imnograful nu foloseşte niciun keyword cu opoziţie faţă de iudei. Am putea foarte simplu aminti aici obsesia liderilor iudaici faţă de furtul din partea Apostolilor a trupului lui 
Hristos $^{42}$ sau mituirea soldaţilor romani de către căpeteniile iudeilor după actul Învierii pentru a salva poporul de ,mitul” Iisus ${ }^{43}$.

\section{De la textul sacru la contextul istoric al epocii lui Roman: diferite interpretări teologice ale perspectivei antiiudaice în condacele romaneice}

Roman, ca şi ceilalţi Părinţi ai Bisericii, este un fidel mărturisitor al textului sacru din care îşi extrage temele pentru condacele sale. Aşa după cum afirmă şi Roger Coresciuc într-o analiză a fidelităţii Sfântului Grigorie Palama faţă de textul sacru, aceasta este rezultatul unei abordări lipsite de pretenţia soluţiilor interpretative proprii:

„Diferența dintre înţelegerea duhovnicească şi cea filosofică este dată tocmai de conţinutul acestei înţelegeri. Sfântul Grigorie Palama precizează că păcatul este principalul obstacol care se poate interpune în încercarea de desluşire a adevărurilor lumii. Înceţoşarea puterii contemplative a sufletului îl aruncă pe om în necunocutul soluţiilor epistemologice proprii’"${ }^{44}$.

În ceea ce îi priveşte pe iudei şi atitudinea lor faţă de Fiul lui Dumnezeu şi Fiul Omului, poetul bizantin face apel atât la episoadele derulate în Săptămâna Patimilor, cât şi la anumite imagini vetero-testamentare (tipologice) prin care face o paralelă

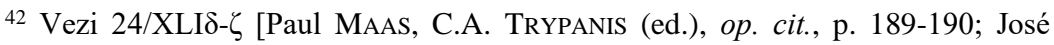
GROSDIDIER DE MATONS (ed.), op. cit., p. 434-436] (trad. rom.: Sfântul RoMAN MELODUL, op. cit., p. 221-223).

${ }^{43}$ Vezi condacele 24/XLI $1 \alpha^{1}-1 \beta^{6}, 1 \theta^{5}$ [Paul MAAS, C.A. TrYPANIS (ed.), op. cit., p. 184-185, 187; José Grosdidier De MATONS (ed.), op. cit., p. 440-442, 448] (trad. rom.: Sfântul RomAn Melodul, op. cit., p. 225-226, 229) şi $25 \kappa^{1-}$ 2/XLIIא ${ }^{1}$ [Paul MAAS, C.A. Trypanis (ed.), op. cit., p. 195; José GrosDidiER DE MATONS (ed.), op. cit., p. 478] (trad. rom.: Sfântul RomAn MElodul, op. cit., p. 243-244).

${ }^{44}$ Roger CoRESCIUC, ,,Triadele Sfântului Grigorie Palama, repere pentru cateheza contemporană”, în Altarul Reîntregirii, 2 (2014), p. 104. 
între poporul iudeu din trecut şi cel din epoca Mântuitorului. Dacă privim cele şase condace ale Învierii ca o compoziţie unitară atunci va trebui să vedem că viziunea antiiudaică a Melodului se observă mai cu seamă în secţiunea biblico-narativă (descrierea pe baza Sfintei Scripturi a evenimentelor din Săptămâna Patimilor, precum sfatul bătrânilor de a-L prinde şi omorî pe Hristos; judecarea lui Hristos şi predarea Lui către Pilat, mentalitatea căpeteniilor iudeilor şi relaţia lor cu Pilat în legătură cu furtul Trupului lui Hristos, paza de la mormântul Domnului şi mituirea soldaţilor de către căpeteniile iudeilor) şi cea istoric-contextuală (identificarea dintre iudei şi eretici cu privire la dumnezeirea lui Hristos).

\section{a) secţiunea biblico-narativă}

Roman recreează în cele şase condace cu temă pascală întreaga imagine dezvoltată de evanghelişti asupra Pătimirilor Domnului. Cum era de aşteptat, Sfântul Roman, ca narator omniprezent $^{45}$, recompune scena săptămânii Patimilor, dublând-o de dramă şi de dialogurile existente între membrii Sinedriului, pe de o parte, şi căpeteniile iudeilor cu procuratorul Pilat din Pont, căruia îi cer cu insistenţă răstignirea lui Hristos. Formele alese de Roman, care sunt la unison cu terminologia liturgică bizantină antiiudaică, subliniază în mod cert răutatea şi nebunia prin care liderii Sinedriului vor ajunge să-L propună pe Hristos lui Pilat spre a fi condamnat. Din această perspectivă el se foloseşte de exprimarea evaluativă a lui $\tau \tilde{\omega} v$ ớvo $\mu \omega v$, termen care nu se referă la evrei la modul general, ci strict la membrii Sanhedrinului ${ }^{46}$. Poporul iudeu, după cum relatează Melodul, este unul „călcător de lege” sau neavând lege ${ }^{47}$, după cum şi ,judecătorii" acestui popor de nelegiuiţi se identifică $\mathrm{cu} \mathrm{el}{ }^{48}$. Este un joc de raportare pe care imnograful bizantin îl face între popor $(\lambda \alpha o ́ \varsigma \tau \tilde{\omega} v$ ơvo $\mu \omega v)$ şi liderii

\footnotetext{
45 J.H. BARKHUIZEN, ,Romanos Melodos: Essay on the Poetics...”, p. 19.

${ }^{46}$ Ibidem.

${ }^{47}$ Vezi formele întâlnite în condacele 24/XLI $\alpha^{3}, 24 / \mathrm{XLI} \alpha^{7}, 24 / \mathrm{XLI} \gamma^{2}, 24 / \mathrm{XLI} \alpha^{3}$, 24/XLI $\gamma^{2}, 24 / \mathrm{XLI} 1 \theta^{2} ; 28 \varepsilon^{2} / \mathrm{XLIII}^{3}, 28 / \mathrm{XLIII} \zeta^{1}$.

${ }^{48}$ Vezi $24 / \mathrm{XLI} \gamma^{2}$.
} 


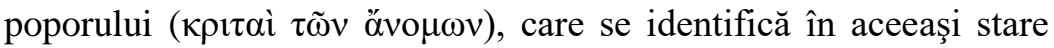
morală degradantă ${ }^{49}$. Linguşindu-se pe lângă Pilat, pe care-l consideră lider al iudeilor şi al altor neamuri ${ }^{50}$, căpeteniile iudaice vor cere atât răstignirea, cât şi păzirea mormântului după moartea lui Hristos, având drept fundament trei realităţi: a) furtul de către Ucenici; b) că El Însuşi a spus că va învia a treia zi din morţi şi c) viu fiind a dezlegat sâmbăta, iar acum Legea o va dezlega prin Învierea $\mathrm{Sa}^{51}$. Dacă primele două aspecte sunt cunoscute textului neotestamentar (Mt. 27:62-64), ultimul aspect este un adaos romaneic, ce are desigur în prim plan perspectiva duhovnicească a Învierii lui Hristos ${ }^{52}$.

Vina pentru uciderea lui Hristos nu este aruncată în versetele romaneice asupra lui Pilat, care doar L-a flagelat pe Hristos, ci pe iudei, căci ei au cerut insistent răstignirea Lui ${ }^{53}$. „Chestiunea Hristos" este una scumpă din perspectivă pecuniară pentru judecătorii iudeilor de vreme ce ,viu sau mort [Hristos] ne costă

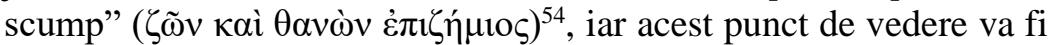
extins după Învierea lui Hristos prin mituirea soldaţilor din partea căpeteniilor iudaice ca acţiune fezabilă de tăinuire a evenimentului ${ }^{55}$.

Într-un singur context intenţia romaneică se bazează pe imaginile vetero-testamentare din cartea lui Isus Navi (6:20-21; 8:24-28; 10:28-29; 11:10-14, 21-22). Este, desigur, o sondare a lui Roman în trecutul poporului iudeu pentru a sublinia juxtapunerea dintre Isus Navi şi iudei versus Iisus şi contemporanii săi. Astfel,

${ }^{49}$ Cf. J.H. BARKhuizen, „Romanos Melodos: Essay on the Poetics...”, p. 272.

${ }^{50}$ Vezi 24/XLI $\varepsilon^{1-5}$.

51 Vezi 24/XLI $\delta^{4}-\varsigma^{5}$. Pentru o analiză a acestor idei, vezi studiul lui: J.H. BARKHUIZEN, „Romanos Melodos: Essay on the Poetics...”, p. 19-20, 273-274.

52 Pentru alte perspective, vezi: J.H. BARKHUIZEN, „Romanos Melodos: Essay on the Poetics...", p. 22.

${ }^{53}$ Vezi $24 / \mathrm{XLI}^{1}$.

54 Vezi 24/XLI1 $\beta^{6}$ [Paul MaAs, C.A. Trypanis (ed.), op. cit., p. 185; José GROSDIDIER DE MATONS (ed.), op. cit., p. 442] (trad. rom.: Sfântul RoMAN MELODUL, op. cit., p. 226).

55 Vezi 24/XLIı-1 $\beta$ şi 25/XLII $\kappa$. 


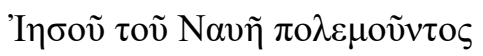

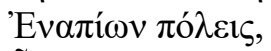

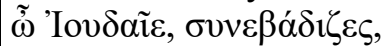
$\theta \varepsilon \omega \rho \tilde{\omega} \nu \dot{\varepsilon} \kappa \chi \varepsilon \delta ́ \mu \varepsilon v \alpha \alpha i ّ \mu \tau \alpha$

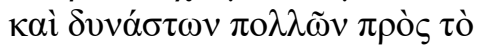

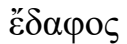

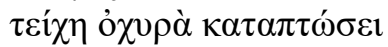
$\tau v \gamma \chi \alpha \dot{\alpha o v} \tau \alpha$

$\tilde{\eta} \lambda \theta \varepsilon v$ 'I $\beta \lambda \alpha ́ \sigma \tau \eta \mu \alpha$

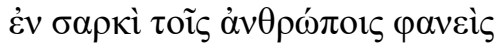

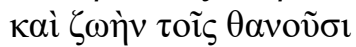
$\delta \omega \rho o u ́ \mu \varepsilon v o \varsigma^{\circ}$

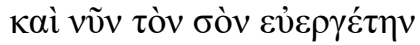

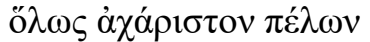
$\kappa \alpha \theta v \pi \circ \beta \alpha \dot{\lambda} \lambda \lambda \varepsilon 1 \varsigma \Pi 1 \lambda \alpha \dot{\tau} \omega \dot{\alpha} \xi 1 \tilde{\omega} v$

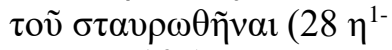
$\left.{ }^{7} / \mathrm{XLIII}^{1-8}\right)^{56}$. ,,pe când Isus al lui Navi purta război cetăţilor potrivnice, iudeule, mergeai alături, văzând tu sângele curgând şi zidurile întărite ale multor stăpânii

surpate la pământ.

Venit-a Iisus, vlăstarul Fecioarei, în trup El oamenilor arătându-se şi dăruind viaţă celor morţi.

Şi acum, cu totul numulţumitor fiind, pe binefăcătorul tău L-ai dat puterii lui Pilat, învrednicindu-L a fi răstignit..."57.

Viziunea romaneică pune în această strofă atitudinea oscilantă a iudeilor: pe de o parte, faţă de Isus Navi, pe care-l urmau în drumul lor spre nimicirea popoarelor, iar pe de altă parte, faţă de Hristos pe care L-au predat lui Pilat din Pont pentru a fi omorât. „Mobilul” acestei atitudini este, desigur, nemulţumirea iudeilor faţă de Hristos, pe care-L doreau a fi un eliberator, un continuator politic al lui Isus Navi, din mâinile celor care-i asupreau. În plus, după cum notează R.J. Reichmuth în teza sa de doctorat dedicată tipologiilor romaneice, ,cel dintâi Isus, cu ajutorul evreilor, a adus moarte şi distrugere, pe când Cel de-al doilea Iisus a adus viaţă celor care au murit" ${ }^{\prime \prime}$.

${ }^{56}$ Paul MAas, C.A. TryPANIS (ed.), op. cit., p. 213; José GrosdidiER DE MATONS (ed.), op. cit., p. 510.

57 Trad. rom.: Sfântul Roman Melodul, op. cit., p. 252-253.

${ }^{58}$ Roland Joseph ReICHMUTH, Typology of the Genuine Kontakia of Romanos the Melodist, 1975, p. 118 (în manuscris; trad. rom.: Tipologia în condacele autentice ale Sfântului Roman Melodul, trad. Valentin Radu Trandafir, ed. 


\section{b) secţiunea istoric-contextuală}

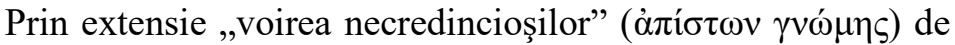
care aminteşte imnograful bizantin ar putea sublinia atât mentalitatea reprezentanţilor iudeilor din timpul Mântuitorului, cât şi pe ereticii din vremea (anterioară sau contemporană) lui Roman, care disociau cele două firi în Hristos şi-L numeau un ,simplu

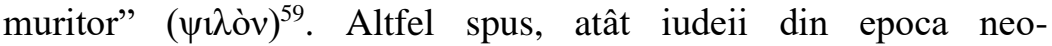
testamentară, cât şi ereticii din perioada bizantină anterioară lui Roman, accentuau firea umană în detrimentul unirii ei reale cu cea dumnezeiască în Persoana lui Hristos, considerându-L doar un om muritor printre cei muritori şi nicidecum drept Fiul lui Dumnezeu Intrupat, deofiinţă cu Tatăl. Este cunoscută realitatea că acest condac 28 la Invierea Domnului are o raportare hristologică impotriva arienilor ${ }^{60}$. Este foarte probabil ca, prin menţionarea iudeilor, imnograful să fie preocupat de a insera aici şi perspectiva teologică eronată a arienilor, care-L vedeau pe Hristos cea mai perfectă (Sic!) creatură şi nicidecum Fiul lui Dumnezeu întrupat, din două firii ${ }^{61}$.

îngrijită, studiu introductiv şi bibliografie de Alexandru Prelipcean, Iaşi, Edit. Doxologia, 2020, p. 132).

59 Paul MAAS, C.A. TRYPANIS (ed.), op. cit., 281 $\gamma^{1 / 4}$, p. 215; José Grosdidier de Matons (ed.), op. cit., XLIII $\gamma^{1 / 6}$, p. 516. Trad. rom.: Sfântul RoMAN MELODUL, op. cit., p. 256.

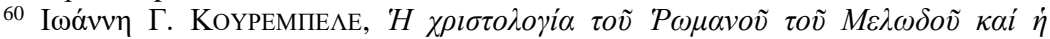

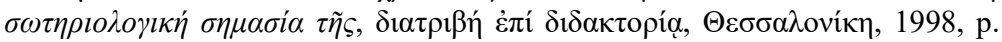
90 (trad. rom.: Hristologia Sfântului Roman Melodul şi importanţa ei soteriologică, trad. Alexandru Prelipcean, Iaşi, Edit. Doxologia, 2018, p. 129).

${ }^{61}$ Ca şi în iconografie, imnografia conduce către o înţelegere autentică a credinţei.

Vezi, spre exemplu, mesajul pe care iconografia îl aduce la Roger CoRESCIUC, „Evoluţia erminiilor de pictură bizantină”, în vol.: Criterii de recunoaştere şi evaluare a picturii bizantine (icoană şi frescă), volumul Simpozionului Internaţional cu acelaşi titlu desfăsurat la Bucureşti, 20-24 mai 2017, Bucureşti, Edit. Basilica, 2017, p. 104: „Icoana care este pictată respectând canonul iconografic oferă această şansă a gustării din lumina descoperită, din lumina care copleşeşte toate celelalte lumini înşelătoare ale lumii. Himerele dispar în faţa acestei lumini, şi omul contemplativ se arată a fi omul care se înfruptă cel mai deplin din fructul, neoprit de această dată, al existenţei în 


\section{Concluzii finale}

Aşa cum am observat deja din rândurile de mai sus, Sfântul Roman Melodul dezvoltă perspectiva antiiudaică doar în cadrul a două condace (dintre cele şase) pe care le dedică Învierii Domnului, şi anume, în condacele 24(XLI) şi 28(XLIII). Termenul de bază pe care Roman îl utilizează cel mai frecvent în relaţie cu perspectiva sa antiiudaică este övouos (fără de lege). Este, desigur, un termen generic cunoscut întregii imnografii bizantine ca numitor comun pentru atitudinea iudeilor faţă de Lege şi faţă de cererea lor absurdă de a fi ucis Hristos, de altfel, un ,personaj incomod” pentru liderii iudaici.

Intenţia antiiudaică a Melodului bizantin este una bivalentă: biblico-narativă (cu accentuarea dialogului liderilor iudeilor de a cere lui Pilat uciderea lui Hristos şi păzirea mormântului Acestuia pentru a evita mai apoi „mitul” Învierii) şi istoric-contextuală (prin valorificarea necredinţei iudeilor ca simbol pentru necredinţa ereticilor în Hristos Cel întrupat). Este foarte sesizabilă în cadrul imnelor sale intenţia dinamică prin care Roman (re)citeşte narațiunea biblică. El nu urmează ad literam relatările evanghelice privind Pătimirile Domnului şi implicarea căpeteniilor iudaice, ci îşi ajustează naraţiunea, creând un dialog dramatic al iudeilor cu Pilat pentru a ,nimici” mitul Hristos.

Din perspectiva istoric-contextuală, Roman se foloseşte de perspectiva biblică şi de raportarea faţă de iudei pentru a-i indica în mod voalat pe arieni, de vreme ce ,centrul învătăturii sale rămâne... Hristos şi mântuirea omului"'62. Este preocupat să redea în mod fidel credinţa pe care o mărturiseşte prin poezia sa teologică sau, mai bine spus, teologia sa poetică. În plus, „orice acuzaţie de antisemitism (în termenul actual al acestui termen) în condacele lui

forma ei cât se poate de reală, iar icoana este poarta concretă către trăirea acestei lumini".

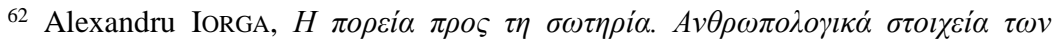

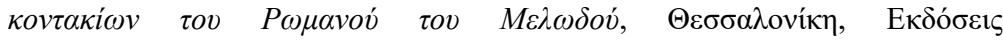

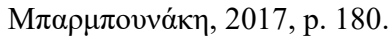


Roman nu poate fi fundamentată" ${ }^{\prime}$, chiar dacă, raportându-se la iudeii din vremea Mântuitorului, poetul-teolog îi are în perspectiva sa pe ereticii Bisericii.

$\cos 8$

\section{Bibliografie}

\section{Izvoare:}

1. ***, Penticostarul, Adică sfintele slujbe de la Duminica Paştilor până la Duminica Sfinţilor români, Bucureşti, Edit. Institutului Biblic şi de Misiune Ortodoxă, 2012.

2. Grosdidier de Matons, José (ed.), Romanos le Mélode. Hymnes (Sources Chrétiennes, 128), Paris, Les Éditions du Cerf, 1967.

3. MAAS, Paul/ TryPanis C.A. (ed.), Sancti Romani Melodi Cantica. Cantica genuina, Oxford, Clarendon Press, 1963.

4. Sfântul Roman Melodul, Imne, trad. Cristina Rogobete şi Sabin Preda, Bucureşti, Edit. Bizantină, 2007.

\section{Literatură secundară:}

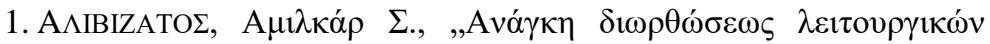

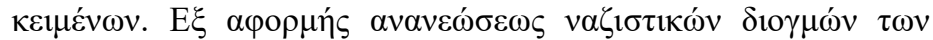

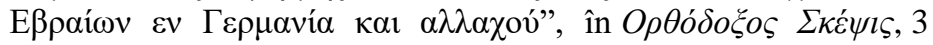
(1960), p. 5-8.

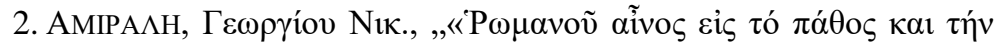

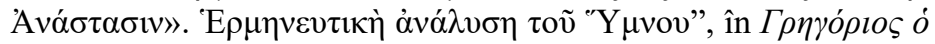

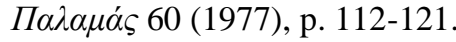

3. AZAR, Michael G., „Prophetic Matrix and Theological Paradox: Jews and Judaism in the Holy Week and Pascha Observances of the Greek Orthodox Church", în Studies in Christian-Jewish Relations 1 (2015), disponibil la https://ejournals.bc.edu/ index.php/scjr/article/view/8658 [accesat la data de 19.09.2020; trad. rom.: „Matrice profetică şi paradox teologic: evrei şi iudaism în Săptămâna Mare, precum şi ritualurile pascale în

${ }^{63}$ Alexandru Iorga, op. cit., p. 180. 
Biserica Ortodoxă”, trad. Alexandru Prelipcean, în Alexandru IONIȚĂ (ed.), Imnografia liturgică bizantină. Perspective critice (Studia Oecoumenica, 13), Cluj-Napoca, Presa Universitară Clujeană, 2019, p. 11-38].

4. IDEM, „Jewish-Christian Relations and Orthodox Ecumenical Participation", în Public Orthodoxy. The Orthodox Christian Study Center of Fordham University, disponibil la https://publicorthodoxy.org/2015/10/22/jewish-christianrelations-and-orthodox-ecumenical-participation/ (accesat la data de 19.09.2020).

5. BARKHUIZEN, J.H., „Romanos Melodos: Essay on the Poetics of his Kontakion «Resurrection of Christ» (Maas-Trypanis 24)", în Byzantinische Zeitschrift 79 (1986), p. 17-28; partea a II-a, p. 268-281.

6. BARTOLOMEO I, „Gli ortodossi e l'ebraismo”, în Gloria a Dio per ogni cosa, Ed. Qiqajon, 2001.

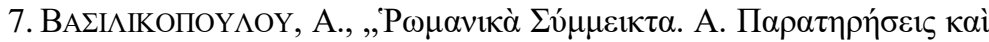

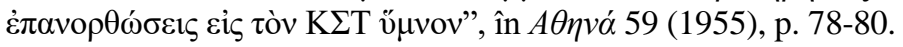

8. BuCUR, Bogdan G., „Anti-Jewish Rhetoric in Byzantine Hymnography: Exegetical and Theological Contextualization", în St. Vladimir's Theological Quaterly 1 (2017), p. 39-60 [trad. rom.: „Retorica anti-iudaică din imnografia bizantină: Contextualizare exegetică şi teologică”, în Alexandru IONIȚĂ (ed.), Imnografia liturgică bizantină. Perspective critice (Studia Oecoumenica, 13), Cluj-Napoca, Presa Universitară Clujeană, 2019, p. 52-77].

9. IDEM, „The Murderers of God, The Lawless Nation of the Jews...: Coming to Grips with Some of Our Holy Week Hymns", în Public Orthodoxy, disponibil la https://publicorthodoxy.org/2018/03/29/bucur-holy-week-2018/ (accesat la data de 19.09.2020).

10. CoHEN, Mireille/ CANERI, Sandrine, „Recontextualiser les Saints Pères et ne pas juger", în Sens 384 (2013), p. 843-849.

11. CORESCIUC, Roger, „Triadele Sfântului Grigorie Palama, repere pentru cateheza contemporană”, în Altarul Reîntregirii 2 (2014), p. 101-123.

12. IDEM, „Evoluţia erminiilor de pictură bizantină”, în vol.: Criterii de recunoaştere şi evaluare a picturii bizantine (icoană şi frescă), 
volumul Simpozionului Internaţional cu acelaşi titlu desfăsurat la Bucureşti, 20-24 mai 2017, Bucureşti, Edit. Basilica, 2017, p. 191-202.

13. GADOR-WHYTE, Sarah Elizabeth, Rhetoric and Ideas in the Kontakia of Romanos the Melodist, Submitted in total fulfilment of the requirements of the degree of Doctor of Philosophy, Center for Classics and Archaeology, The University of Melbourne, 2011.

14. GROEN, Bert, „Attitudes towards Judaism in Greek-Byzantine Liturgy: Anti-Judaism in Holy Weeks Text and the Appreciation of Israel's Righteous", în Analecta Bruxellensia 12 (2007), p. 81-93.

15. IDEM, „Anti-Judaism in the Present-Day Byzantine Liturgy”, în Journal of Eastern Christian Studies 60 (2008), p. 369-387.

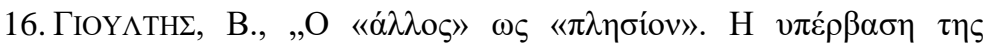

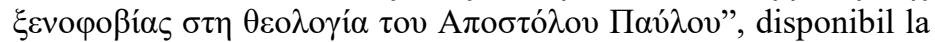
http://old.imd.gr/article_print/1512 (accesat la data de 29.11.2020).

17. Hunger, H., Reich der Neuen Mitte, Graz, 1965.

18. IONIȚĂ, Alexandru, „Old Wine in New Wineskins: Romans 9-11 as a Possible Biblical Source for a New Hymnography of the Holy Week", în Ivan MoOdY, Maria TAKALA-RosZCZENKO (ed.), Creating Liturgically: Hymnography and Music. Proceedings of the Sixth International Conference on Orthodox Church Music, University of Eastern Finland, Joensuu 8-14 June 2015, The International Society for Orthodox Church Music, 2017, p. 228-243 [trad. rom.: „Vin vechi în burdufuri noi: Romani 9-11 ca sursă de inspiraţie pentru noi creaţii imnografice", în Alexandru IONIȚĂ (ed.), Imnografia liturgică bizantină. Perspective critice (Studia Oecoumenica, 13), ClujNapoca, Presa Universitară Clujeană, 2019, p. 95-120].

19. IDEM, „Patristic and Eastern Orthodox Interpretations of Romans 9-11: Overview and Perspectives for the Theological Recovery of a Pauline Text", în Benyik GYÖRGY (ed.), Interpretations of the Letter to the Romans, Szeged, Jate Press 2018, p. 113-123.

20. IDEM, „Byzantine Liturgical Hymnography: a Stumbling Stone for the Jewish-Orthodox Christian Dialogue?", în Review of Ecumenical Studies 2 (2019), p. 253-267. 


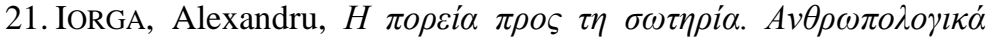

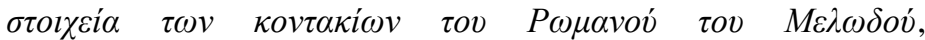

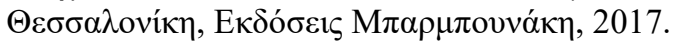

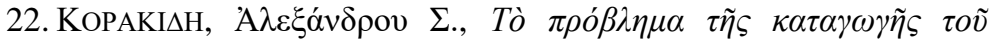

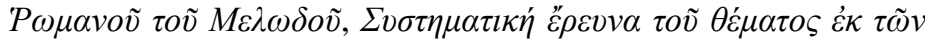

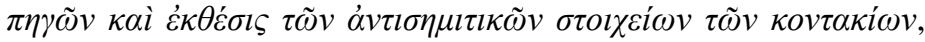
A $\theta \tilde{\eta} v \alpha 1,1971$.

23. Koumarianos, Pavlos, „Liturgical Problems of Holy Week”, în St. Vladimir's Theological Quaterly 46 (2002), p. 3-21.

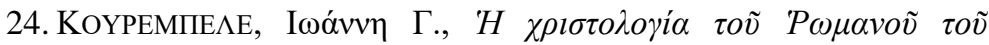

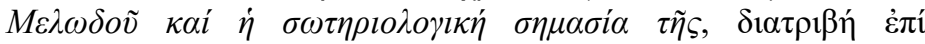

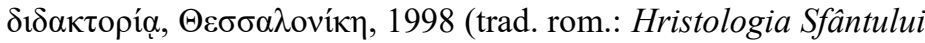
Roman Melodul şi importanţa ei soteriologică, trad. Alexandru Prelipcean, Iaşi, Edit. Doxologia, 2018).

25. KRATZERT, Thomas, „Wir sind wie die Juden”: Der griechischorthodoxe Beitrag zu einem ökumenischen jüdisch-chrislichen Dialog, Istitut Kirche und Judentum, Berlin, 1994.

26. LEVINE, Amy-Jill, „Holy Week and the hatred of the Jews: How to avoid anti-Judaism this Easter", disponibil la https://www.abc.net.au/religion/holy-week-and-the-hatred-of-thejews/11029900 (accesat la data de 19.09.2020).

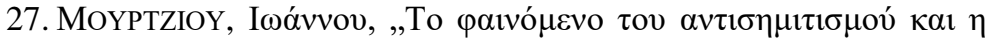

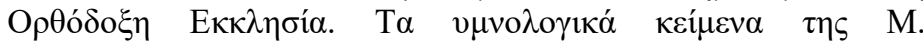

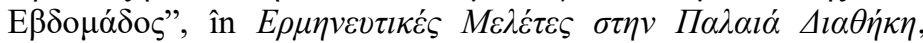

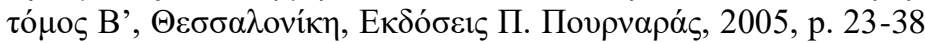
[trad. rom.: „Fenomenul antisemitismului şi Biserica Ortodoxă. Textele liturgice ale Săptămânii Patimilor", trad. Alexandru Prelipcean, în Alexandru IONIȚĂ (ed.), Imnografia liturgică bizantină. Perspective critice (Studia Oecoumenica, 13), ClujNapoca, Presa Universitară Clujeană, 2019, p. 39-51].

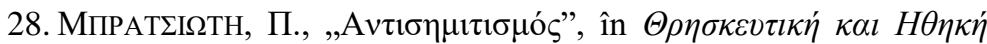

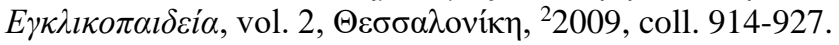

29. PENTIUC, Eugen J., „Orthodoxy and Judaism”, în John Anthony MCGUCKIN (ed.), The Concise Encyclopedia of Orthodox Christianity, Wiley Blackwell, 2014, p. 286-288.

30. PRELIPCEAN, Alexandru, „Romanos' Renaissance”. From the beginning to the present. Bibliography about Romanos the 
Melodist, With a preface by Martin Tamcke (Studien zur Orientalischen Kirchengeschichte, 61), Berlin-Münster-WienZürich-London, LIT Verlag, 2019.

31. IDEM, „Гर́vo $\mu ⿱ \dot{\varepsilon} v \dot{\varepsilon} \xi \dot{\varepsilon} \beta \rho \alpha i ́ \omega v$ or the Jewish origin of Romanos the Melodist: From overestimations to underestimations and finding bridges between the West and the Orient", în Review of Ecumenical Studies 2 (2019), p. 199-208.

32. ReICHMUTH, Roland Joseph, Typology of the Genuine Kontakia of Romanos the Melodist, 1975, p. 118 (în manuscris; trad. rom.: Tipologia în condacele autentice ale Sfântului Roman Melodul, trad. Valentin Radu Trandafir, ed. îngrijită, studiu introductiv şi bibliografie de Alexandru Prelipcean, Iaşi, Edit. Doxologia, 2020).

33. THEOKRITOFF, Elizabeth, „The Orthodox services of Holy Week: The Jews and the New Sion", în Sobornost incorporating Eastern Churches Review 25 (2003), p. 25-50.

34. Van Sichem, P., „Een opstandingskontakion van Romanos de Melode als voorbeld van zijn dichtkunst", în R. THIBAU, H. DE LEY (ed.), Avó $\mu v \eta \sigma l \varsigma$, Gedenkboek E. A. Leemans, Brügge, 1970, p. 385-400.

35. VoICESCU, Mihail, „Învierea Domnului în creaţia imnografică a Sfântului Roman Melodul”, în Glasul Bisericii 4-5 (1983), p. 239-250.

36. ХАгтОҮПН, А (1984), p. 101-118. 